\title{
Evocación del Profesor Alonso Zamora Vicente desde la distancia
}

\author{
Ángel Iglesias Ovejero ${ }^{1}$
}

Recibido: 30 de marzo de 2017 / Aprobado 4 de octubre de 2017

Resumen. Este modesto homenaje a D. Alonso Zamora Vicente es una evocación personal por parte de un antiguo alumno "retraído", catedrático de universidad en Francia. Después de una breve introducción, se articula en cuatro secciones la figura de un gran humanista: el ambiente estudiantil en la Facultad de Filosofía y Letras de la Universidad de Madrid (Complutense) en los años sesenta, el profesor de Lingüística, el director de tesis y el maestro tutelar. Incluye un apéndice de cartas de Don Alonso que ilustran una relación marcada por el respeto y el afecto recíprocos.

Palabras clave: Alonso Zamora Vicente; Universidad Complutense de Madrid; dialectología española; El Rebollar.

\section{[fr] Evocation du Professeur Alonso Zamora Vicente à distance}

\begin{abstract}
Ce modeste hommage au Professeur Alonso Zamora Vicente est une évocation personnelle de la part d'un ancien élève "réservé", Professeur des universités en France. Après une brève introduction, cette évocation s'articule en quatre sections sur la figure d'un grand humaniste: l'ambiance du monde étudiant à la Faculté des Lettres de l'Université de Madrid (Complutense) dans les années soixante, le professeur de Linguistique, le directeur de thèse et le maître tutélaire. Cela est suivi d'un appendice contenant quelques lettres de Don Alonso qui manifestent une relation marquée par le respect et l'affection réciproques.
\end{abstract}

Keywords: Alonso Zamora Vicente; Universidad Complutense de Madrid; dialectologie espagnole; El Rebollar.

Sumario: 1. Introducción; 2. Ambiente universitario de Madrid en los años sesenta; 3. El Profesor de Filología y Dialectología; 4. El Director de tesis; 5. El Maestro permanente; 6. Colofón; 7. Referencias bibliográficas; 8 . Apéndice: Ilustraciones y correspondencia.

Cómo citar: Iglesias Ovejero, Á. (2017). Evocación del Profesor Alonso Zamora Vicente desde la distancia, en Revista de Filología Románica 34. Núm. especial, 171-196.

\section{Introducción}

El itinerario artístico de Alonso Zamora Vicente en Francia no se ha beneficiado de un contexto muy favorable. Por un lado, debido a que el hispanismo francés ha estado condicionado por su fuerte raigambre republicana española y todavía en la época del tardofranquismo se percibía en él cierta animosidad contra la cultura oficial de España. Por otro lado, en la formación universitaria de los hispanohablantes 
y particularmente de los que se destinan a la enseñanza del español se tiende a una programación monográfica, centrada sobre todo en la literatura clásica y desde una perspectiva social (civilizacionista), en la que se ha ido abriendo paso el interés por la literatura y el ancho mundo de Latinoamérica (un término que los franceses han contribuido a promocionar en detrimento de la designación tradicional de Hispanoamérica, cuya referencia es en parte excluyente con respecto a países de no hispanohablantes y, de por sí, irradia connotaciones un tanto molestas).

En este contexto, aunque parezca falta de modestia decirlo, la imagen de Alonso Zamora Vicente es la que sus alumnos españoles, relativamente numerosos en el país vecino, han transmitido. Otro tanto cabría decir de los hispanistas franceses, sobre todo los becarios de la Casa de Velázquez, que tuvieron la suerte de seguir los cursillos monográficos de Don Alonso, pero se tiene la impresión de que él mismo no hizo gran cosa por promocionarse en el país vecino desde los años setenta, cuando fue nombrado secretario de la Real Academia (1971). Antes debió de ser profesor visitante en París, pero después no se agarró a la fórmula de compartir publicaciones, al modo de Manuel Alvar y Bernard Pottier, y otros experimentos universitarios, incluidas direcciones bicéfalas de tesis, que eran reconocidas en Francia y España, mucho antes de que se implantaran los planes de estudio iniciados en el proceso de Bolonia (1999). No se tiene noticia de que aceptara propuestas para ir de profesor invitado, repetidamente formuladas en Orleans. Al parecer, el secretariado de la Real Academia y otros compromisos no le dejaban tiempo libre, pero además, con la jubilación, se volvió algo aprehensivo ("nos hemos hecho viejos de repente") y reacio a los oropeles oficiales, aunque procurara evitar desaires innecesarios.

En general, seguramente todos sus alumnos coinciden en considerar al Maestro como un gran filólogo, anclado en un conocimiento de la lengua y sus variedades a partir de una rica experiencia sobre el terreno en dos continentes, muy sensible y abierto a la expresión artística literaria (así como a otras artes) del ancho mundo hispánico (u otras corrientes) y un gran académico, a la vez riguroso en los fundamentos y flexible en la forma (algo escéptico con respecto a los experimentos "científico-lingüísticos"). Un humanista de una inmensa cultura, en suma.

\section{El ambiente universitario de Madrid en los años sesenta}

Ya avanzada la década de los sesenta, el profesor Alonso Zamora Vicente impartía clases en la sección de Filología Hispánica, que, al parecer, se había creado como alternativa a la de Filología Románica. Ésta dejó de funcionar durante un año o dos, es de suponer que en relación con la jubilación de Dámaso Alonso, y se repondría poco después. Entre tanto se ocupaba de los asuntos pendientes la profesora de Filología Gallega y Portuguesa, Pilar Vázquez Cuesta, hasta que D. Alonso ocupó la cátedra. La verdad, el seguimiento de estos avatares no estaba al alcance de quien no sentía un interés excesivo por los arcanos de la Administración universitaria, de modo que se perdió el año de creación de la Filología Hispánica, más que nada debido a su complicada vida y por estar enredado con los estudios de Filología Clásica, que no llegó a culminar. La nueva sección tenía dos ramas gemelas, que, al menos en teoría, correspondían a las Ciencias del Lenguaje y a las Ciencias de la Literatura. En el cómputo del alumnado estaban muy desequilibradas. La mayoría de los aspirantes a filólogos se decantaba por la subsección de Literatura. En la de Lin- 
güística había un par de docenas de alumnos o poco más, pero relativamente variado en su composición, con un par de religiosos o tres, algunos ex seminaristas, pluriempleados y rebotados de otros departamentos o facultades. Una decena de ellos no aparecen en la adjunta fotografía de fin de carrera. Había chicos y chicas, casi mitad por mitad, pero ellas eran también mayoría, aunque menos pronunciada que en la otra subsección: tres extranjeras, una aspirante a monja y varias que, para quien arrastraba un sustrato campesino y algo machista, parecían un poco mojigatas entonces (y éstas, en justo retorno, lo tenían por algo agreste, sin duda porque no se esforzaba mucho por disimular el pelo de la dehesa). Buena gente, en general, pero bastante encorsetada en la sociedad del estado franquista, al que en apariencia se adaptaba la mayoría y en el que algunos no acababan de encajar.

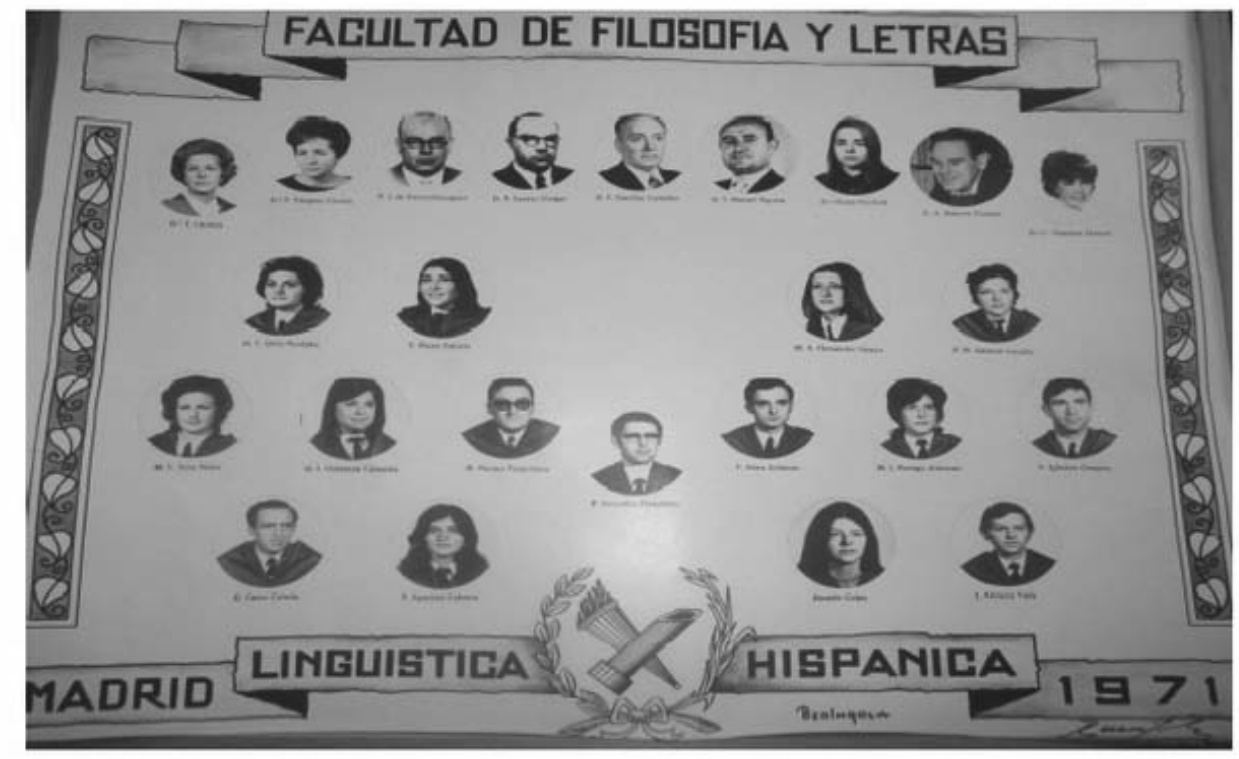

Figura 1: Orla de la sección de Filología Hispánica. Promoción de 1971.

En el mundillo universitario de la Universidad de Madrid (primero Central y después Complutense) el desertor del campo y la ciudad provinciana se sentía como gallina en corral ajeno, porque hasta allí alcanzaba la sombra de un sistema represivo como aquél, en que la sospecha de todos contra todos se erigía en norma y hasta los dedos se volvían huéspedes. En el segundo lustro de los años sesenta la Dictadura se había ablandado un poco, pero la bestia solo estaba dormida. Los estudiantes, con incipientes sindicatos democráticos, protestaban y tiraban piedras a la Policía, pero el objetivo (si es que lo era) de echar abajo a Franco y a los suyos resultaba una quimera de inmediato (y de hecho los cambios sustanciales no se produjeron hasta la muerte del Dictador, casi diez años más tarde), pues, aparte de la huelga indefinida (un lujo que muchos estudiantes no podían permitirse de ningún modo), no había una estrategia clara y el seguimiento era de lo más incoherente, por falta de madurez y exceso de frivolidad. Un día la tomaban con un profesor de Historia y proponían expulsarlo (como si ello estuviera en su mano). Poco después había cola 
a la puerta de su despacho para lamerle los pies, y "Don Julio", que no sería tan malo como profesor ni tan rencoroso como persona, disimulaba el perdón haciendo glosas histórico-onomásticas sobre los apellidos de los suplicantes. Los chicos, en el caso de que tuvieran prórroga para el servicio militar y no fueran hijos de militares, por si acaso, se buscaban el amparo de algún oficial superior a través de compañeras que lo tuvieran en su familia. El pato lo pagaba quien pasara por allí y no anduviera listo, porque, entre los alumnos con inquietudes democráticas, unos eran acróbatas con red y otros solo acróbatas.

Con aquellas pedradas y apresuradas carreras la Policía tenía un buen pretexto para merodear por toda la Ciudad Universitaria e incluso, saltándose a la torera el fuero universitario, para entrar en los edificios, en concreto, en la "Casa Madre" de Filología y la "Caja de Cerillas" adjunta - hoy Facultad de Geografía e Historia-, una vez desalojados los incómodos inquilinos de "Políticas y Económicas". Al final, los "Grises" acamparon con sus camionetas cerca de la entrada de estos edificios, en los que, al menor rumor, avisados sin duda por los bedeles y falsos compañeros, entraban como Pedro por su casa, pero con porras en la mano. La Policía sabía de algunos estudiantes y de sus familias tanto o más que los mismos interesados. Y cuando te llamaban a la Dirección General de Seguridad, por ser delegado de curso, afinidad sindical o algo por el estilo, si no te dabas por enterado, te ponían al corriente de tus "antecedentes penales" y los de tu familia, que, sobre todo cuando se relacionaban con la responsabilidad civil o militar de los padres, ya castigados tiempo atrás, al parecer se heredaban, sin necesidad de testamento. En el mejor de los casos, si abjurabas de las herejías republicanas y de tus posibles disidencias antifranquistas, podías pedir un certificado que te permitiría solicitar becas y apuntarte a las milicias universitarias, con eventual derecho a lucir galones y gorra de plato en verano. De no ser así, ni becas ni puñetas. Era el caso del universitario aspirante a disfrutar de toda la libertad que se puede tener en una dictadura. A no ser que actuara por espíritu de contradicción o por innata vocación romántica de marginal, porque esta veleidad le llevaría quizá a elegir siempre temas marginales en sus estudios, con poca o ninguna "salida" práctica: lenguas muertas, moribundas u olvidadas y dialectos residuales, culturas orales menospreciadas, saberes populares, nombres de gente sin renombre, memorias ignoradas o silenciadas de personas represaliadas.

En aquel mundillo de la tercera década franquista los mismos profesores, a excepción de algunos claramente adaptados al sistema, solían ser muy discretos. La seriedad profesoral era un carácter impreso en los miembros del Opus Dei, aplicados y cumplidores, pero nada estimulantes. De otros trascendía un tufillo germanófilo y elitista, como era el caso de los indo-europeístas, helenistas y latinistas de Filología Clásica ("la llave para adentrarse en los únicos estudios relativamente serios de esta Facultad es el conocimiento previo del alemán”, porque, decía uno, solo en esta lengua existían estudios importantes sobre aquellas materias). Pero, en general, la mayor parte de las lecturas recomendadas u obligadas en Filología tenían por autores a alemanes (K. Vossler, K. Bühler, R. Lenz), austríacos (L. Spitzer), suizos (K. Baldinger, C. Bailly, W. Meyer-Lübke, F. de Saussure), italianos (G. Ascoli, B. Croce), rumanos (I. Iordan, E. Coseriu), checos (Círculo Lingüístico de Praga, en la que participaban rusos como N. Trubetzkoi y R. Jakobson) y daneses (L. Hjemslev, K. Togeby), que más o menos pertenecían o tenían acceso a la cultura germana. 
Los profesores de la Central / Complutense que entraban con calzador en aquel Régimen represivo, antiguos depurados o regresados de la emigración obligada o voluntaria para sobrevivir en la "España de Franco, porque no había otra" (dixit Alonso Zamora) se reconocían por el encendido recuerdo de los Regeneracionistas, la Institución Libre de Enseñanza y el Centro de Estudios Históricos en el que ellos mismos se habían formado o iniciado sus estudios. Se referían a la cultura del período anterior a la guerra civil como una edad casi dorada, en abierto contraste con la penuria reinante en la postguerra, de hambruna social y miseria intelectual incluso en la capital del Nuevo Estado, que se nutría de "las glorias imperiales" (contaba D. Alonso que, por entonces, en la Facultad de Filosofía y Letras madrileña no había catedrático de griego y fue necesario habilitar a un eclesiástico que era buen helenista). Estas revelaciones vinieron con el tiempo. Rafael Lapesa era de los más discretos, aferrado a su meticuloso y severo ejercicio de la función docente y académica. Solo años después, en el coloquio posterior a una lectura de tesis, dejó entrever atisbos de la depuración que había soportado en su traslado a Salamanca, donde pervive su recuerdo en algún antiguo alumno nonagenario (como Matilde Garzón Ruipérez, que fue profesora de latín y cuyo padre murió a consecuencia de una enfermedad contraída en el campo de concentración de Gurs [Pirineos Atlánticos], y sin alcanzar a ver libre a su esposa y madre de aquélla, Leonor Ruipérez, que cumplía condena en la cárcel de Saturrarán [Motrico]).

\section{El Profesor de Filología y Dialectología}

Cuando Alonso Zamora empezó a impartir clases de Dialectología en la subsección de Lingüística Hispánica no era catedrático, después de haberlo sido, ni todavía ocupaba el cargo de secretario de la Real Academia (1971), como sucesor de Rafael Lapesa. La primera impresión que dejaba su talante de docente es que en aquellas clases de iniciación a la Filología y específicamente a la Dialectología andaba muy sobrado (a diferencia de algún colega suyo que explicaba la literatura hispanoamericana apoyándose en el dedo índice de la mano derecha). Y esto se traducía en su lenguaje corporal, tanto que no necesitaba de posturas demasiado profesorales, aunque era cuidado en su atuendo y persona. Sentado en la silla detrás de la mesa que le correspondía, comunicaba en el aula con sus alumnos mediante una mirada franca y directa desde el primer día, como si los conociera de antes. Sonreía con frecuencia y algo de socarronería, e incluso reía, pero no a carcajadas, sin desentonar ni ofender. Tenía un discurso informal, casi coloquial, entreverado de una terminología apropiada, sin rehuir los tecnicismos y neologismos necesarios ni caer en la pedantería, que debía de producirle sarpullido. Actualizaba e incluso personalizaba los conceptos (si hablaba de arcaísmos, ejemplificaba con su nombre de pila: "Alonso es también un arcaísmo"). Su método resultaba más sugestivo que sistemático ("sembraba inquietudes", en palabras de un compañero, más que certezas, tarea que consideraría del dominio personal). Practicaba de un modo sutil la ironía (no burla), combinada con imágenes expresivas poco académicas, referidas al entorno sociopolítico. Quizá en ello hubiera también cierto reflejo de aquel ambiente hostil, ya evocado, que obligaba a nadar y guardar la ropa, utilizando un lenguaje ambiguo y un estilo polifónico. 
Don Alonso interpelaba a sus alumnos en clase y dejaba que le hicieran preguntas, que él mismo provocaba, y así abría el horizonte de estudio de más de uno casi desde las primeras clases. A su modo practicaba la interacción democrática desde la presentación de la materia, solicitando opiniones sobre el método a seguir: clase magistral o lecturas comentadas. Alguien, quizá un veterano de otras lides, proponía (propuso) una fórmula mixta: dejar al profesor cierta libertad de expresión y para el trámite de la materia exigible en los exámenes recurrir también al "clásico manual". Este método convenía al Profesor (autor de un clásico manual de Dialectología 1960) y, en términos zamorienses, a los "alumnos guadiana", que eran aquellos que aparecían y desparecían por causas ignoradas, pero presumibles. Porque se les agotaba el caudal otoñal de la curiosidad conforme avanzaba el curso y solamente perseveraban en las clases más interesantes o porque tenían que ganarse la cagada de lagarto como podían; pero lo más probable es que estas dos causas fueran perfectamente compatibles. Los afortunados que eran capaces de sacar algo en limpio de los apuntes tomados en las clases podían asegurar las notas brillantes con este método (clase + libro), que era como llevar cinturón y tirantes. Don Alonso no era muy dado a suspender a nadie e, incluso, alguna vez propuso que cada alumno se pusiera la nota que creyera merecer y con la venia de los compañeros, un ensayo que pudo dar resultado en aquel curso de contingente reducido.

En cuestión de método, en general, el filólogo Alonso Zamora, parecía algo ecléctico e incluso escéptico a veces, pero conocía bien los clásicos de la materia. En la subsección de Lingüística el comparatismo era de rigor en el conocimiento del origen, afinidades y contrastes de las lenguas y dialectos de la Península (apenas evocados los arcanos del ibero-vasquismo) y del ancho Mundo Hispánico. La disciplina entroncaba con una larga tradición que remontaba al siglo XIX e incluso a épocas anteriores, cuando se empezó por determinar el parentesco de las lenguas indoeuropeas a raíz del descubrimiento y análisis del sánscrito entre los siglos XVIII y XIX, que sería la base de la Filología Clásica. Sobre este modelo se encadenó la Filología Románica, centrada en las analogías y divergencias entre las lenguas neolatinas, en las que se habían moldeado y se moldeaban copiosas literaturas nacionales e internacionales. Por ello, la misión de los futuros filólogos era la depuración, edición y análisis de los textos (“a ver, si no, ¿quién lo va a hacer?", Magister dixit).

Era lógico que, con tales objetivos, el comparatismo se aplicara en Literatura, dentro de la lengua en cuestión (orígenes, épocas y estilos) y fuera de ella, entre diversas literaturas nacionales. Esta apertura literaria era muy estimulante, pero los conocimientos y lecturas de los aspirantes a filólogos no se traducían (al menos en la subsección de Lingüística) en aplicaciones prácticas, sobre todo cuando las comparaciones literarias se extendían a otras formas de expresión artística, como la pintura y la música, esta última fuera del alcance de la mayor parte del alumnado. El mismo D. Alonso señalaba veladamente las limitaciones en la formación literaria de sus alumnos "lingüistas", sin nombrar a sus colegas, a diferencia de las afinidades que reconocía abiertamente con otros y con determinados autores o investigadores (como Camilo José Cela o Julio Caro Baroja, cuya docencia echaba de menos en la Universidad). Por ejemplo, no compartía la opinión de considerar un pícaro a Marcos de Obregón ni le parecía normal la escasa importancia que se le concedía en el curso académico a Cervantes ("si el Quijote era la obra máxima de la literatura española, en la universidad de Madrid debía explicarlo el mejor cervantista”). Ironías de 
este tipo eran frecuentes en el Profesor de Filología, que, al menos en público, evitaba criticar a sus colegas, con quienes en general mantenía relaciones de cortesía.

En materia de análisis literario, Alonso Zamora se inscribía en la corriente de la Estilística, cuyas raíces también remontaban al siglo XIX, pero sus diversas modalidades estaban en el apogeo en la generación anterior o próxima a la suya (eran de obligada lectura B. Croce, K. Vossler, L. Spitzer, D. Alonso y A. Alonso, etc.). Pero él mismo, además de practicar afinadas explicaciones de las producciones de autores clásicos y modernos, también era forjador de un estilo personal, caracterizado por la imbricación de la norma coloquial en la escritura literaria e incluso, como se ha indicado, de un estilo pedagógico oral, adaptado al nivel del alumnado.

Así pues, la Filología, por su necesaria relación con la Historia y la Crítica Literaria, tenía un carácter pluridisciplinar ("la philologie mène à tout", según La leçon, de E. Ionesco 1951). Y Alonso Zamora era un excelente filólogo, que hasta cierto punto ofrecía propuestas innovadoras análogas a la de la intertextualidad, que, sin ese nombre, por aquellos años se practicaba ya (se tendía a englobar todo en la noción de contexto, que también servía en la Pragmática), aunque el desarrollo del concepto fue obra del ruso M. Bajtín, hasta que a principios del siglo XXI se redescubrió y se propuso como una novedad en los estudios universitarios, concretamente en Francia.

La misma Dialectología era una disciplina polifacética, estrechamente vinculada a la antropología social y cultural, como rezaba el título de una revista creada en 1944: Revista de Dialectología y Tradiciones Populares. La recogida de materiales, de por sí era enriquecedora, sobre todo si se utilizaba el método de "palabras y cosas" (también de inspiración germánica), pues obligaba al conocimiento del referente para bucear en la etimología y aquilatar el significado del signo, ejercicio de semántica que contrastaba con la anterior preferencia acordada a las "leyes fonéticas". La mejor manera era dejar a los hablantes que se explayaran sobre sus modos de vida y costumbres, lo que solía traducirse en "relatos de vida", antes de que se llamaran así o de otra manera (etnotextos, relatos testimoniales, etc.) y tuvieran tanta importancia en las ciencias sociales, por no hablar de la historia reciente (memoria histórica). A pesar de todo, el neo-dialectólogo (como la primera categoría de "locos", según Erasmo) estaba inclinado a buscar las peculiaridades de sonidos o palabras, el testimonio original, en detrimento de la vigencia real de los fenómenos, y a no distinguir, por ejemplo, entre las características de los dialectos antiguos y los resultados dialectales modernos. (El Profesor prevenía contra otros riesgos, como el manejo de la etimología, "que es muy resbaladiza").

Don Alonso parecía sentir menos entusiasmo por el estructuralismo, que también había surgido entre los autores de las corrientes históricas. El mismo Ferdinand de Saussure, considerado el padre de la lingüística moderna, se había formado al contacto de los comparatistas y los neo-gramáticos. Quizá esto le ayudaría a formular uno de sus más firmes postulados: la diacronía y la sincronía de las lenguas. Nadie discutía tampoco, en esencia, su análisis de la naturaleza binaria del signo lingüístico (significante / significado), aunque admitiría interpretaciones divergentes en su aplicación a otras ramas de las ciencias humanas (antropología, poética, psicología), así como la diferencia entre lengua y habla, o lengua y discurso. En la escuela española la sombra de Menéndez Pidal era alargada y predominaba todavía el interés por la diacronía, más rentable en Dialectología, en la que, por ejemplo, las oposiciones 
fonemáticas estaban lejos de ser evidentes para todos (“-Don Alonso, parece que el sistema consonántico tiene muchas casillas vacías. -Todas”). Y ¿qué decir del Generativismo y la Pragmática, que, sin ser una novedad absoluta, tomaba vuelo en los años setenta? Cuando se leyó la tesis sobre El habla de El Rebollar, el miembro más joven del tribunal (un discípulo de M. Alvar) creyó oportuno señalar que allí había bastante "de Pragmática", término que no aparecía en el texto, y al director, Alonso Zamora, le sentó mal. Al fin, sin ir más lejos, en la misma Facultad, por entonces, Manuel Criado (1980) elaboraba la Estructura general del coloquio, que tampoco utiliza aquel palabro.

Entre los lingüistas que, de más cerca o más lejos, siguieron la senda de Ferdinand de Saussure, era obligada y provechosa la lectura de Eugenio Coseriu. Su análisis del lenguaje establecía tres niveles, el sistema, la norma y el habla (funciones abstractas, usos establecidos, comunicación concreta). Esto podía ser de interés en dialectología, pues distinguía entre norma diatópica, definida por las constantes de uso entre hablantes de un espacio determinado (geolecto), norma diastrática, condicionada por el nivel social de los hablantes (sociolecto) y norma diafásica, de características motivadas por la situación de comunicación (registros). Entre los dialectólogos solamente Vicente García de Diego (1946) había tratado de los "dialectos internos verticales" y la interacción entre los elementos constitutivos de la comunicación lingüística (interlocutores, situación y contexto) era preocupación central de la Pragmática. La Sociolingüística, que inicialmente se ocupaba de los ámbitos urbanos, tenía en cuenta todas esas variedades lingüísticas y, entre otros métodos, incluiría la estadística. En definitiva, los resultados de cualquier tipo de encuesta lingüística están condicionados por los prejuicios que determinan la pregunta.

\section{EI Director de tesis}

Don Alonso Zamora se preocupaba por el destino de sus alumnos que, por lo general, se circunscribía al horizonte de la enseñanza secundaria o superior. La formación pedagógica no estaba prevista en los cursos de la licenciatura universitaria, sino posteriormente, una vez despejada la incógnita de la orientación profesional. Por tanto, no había una formación prevista para lectores o profesores contratados en el extranjero. En el último curso, con su estilo llano habitual, el Profesor sugería la posibilidad de embarcarse en la preparación de una tesis ("si no había que empezar a ganarse el garbanzo enseguida"). Como se indicó más arriba, daba por hecho que en el alumnado de sus clases se hallaban los futuros especialistas de la lengua y la literatura española. En lo que tal vez no estuviera completamente al día era en la circunstancia de que para asistir a clase, y por circunstancias también evocadas, ya había alumnos que tenían que "ganarse el garbanzo". De modo que se trataba, en parte, de perseverar en el modus vivendi, porque la curiosidad intelectual quizá estuviera sembrada de antemano.

Podía suceder que, por ejemplo, en las primeras clases sobre el panorama lingüístico de la Península se te habían aclarado en parte aquellas dudas que tuvieras sobre la naturaleza de las palabras que, utilizando argumentos de estaca, te corregía el maestro de escuela en El Rebollar natal: no burru sino burro, no madri o mairi sino madre, no metá ni buil sino mitad y boil, no entriega sino entrega, no matancia sino matanza, no abruñu sino bruño, no puíu ni comíu sino podido y comido, no 
redi sino red, no p'aqui sino para aquí, no lambel sino lamer, no julgal (pronunciado [hulgál]) sino juzgar, no palral sino parlar (y mejor hablar), no idil sino decir, no jadel ni jidun (pronunciados [hadél] y [hídun]) sino hacer e hicieron, no mojosu sino mohoso, no lesna sino lezna, no meyodía sino medio día, no peñiscal sino pellizcar, no templanu ni praza sino temprano y plaza, no calni sino carne, no agarrami sino agarrarme, no la sé sino la sed, no vati sino water, etc. (Iglesias Ovejero 2010:39). Aquellas palabras mal dichas en castellano, según el maestro, eran parte de una variedad dialectal. Ramón Menéndez Pidal (que se había hospedado en El Collado de Malvarín, propiedad de los Sánchez-Arjona mirobrigenses en el término de El Bodón) lo había señalado en El dialecto leonés (1906), incluyendo esa variedad en el leonés oriental o leonés del sur (que hoy se tienden a separar del área propiamente leonesa), y otros lingüistas alemanes y españoles habían estudiado aspectos relacionados con el dominio asturleonés, los arcaísmos castellanos o las habla extremeñas, en una zona en que el hibridismo lingüístico también implica el componente gallego y portugués.

Alonso Zamora había visitado aquel rincón de la provincia de Salamanca en compañía de Juan Maluquer y Luis Cortés por los años cincuenta, para recoger cuentos tradicionales en la modalidad vernácula de El Payo y Peñaparda, tres de los cuales fueron publicados más tarde por el último en su colección de Cuentos populares salmantinos (Salamanca, 1979): "El gallo y el caballo", "Los tres consejos" y "El pajaritu que habla" (Cortés 1979: I 158-160 y 275-277, II 107-109). El Profesor estaba interesado en la dirección de la investigación. Se podía profundizar el estudio de la situación lingüística de aquella zona, sin tradición cultural escrita, cuya peculiaridad, con anterioridad al siglo XX, no había llamado la atención de nadie, a no ser la de un viajero del siglo XVIII: Diego Alejandro de Gálvez, canónigo de la catedral de Sevilla, que desde esta ciudad realizó un viaje desde Sevilla a Santiago de Compostela en 1755, pasando por Villasrubias y Robleda. Pero la observación, fragmentaria, se desconocía hasta que José Ignacio Martín Benito la puso de relieve hace poco. Gálvez encontraba "sencillo" el trato de la gente y "bastardo" su lenguaje castellano:

Todas estas gentes son de trato sencillo y natural, sin doblez; háblanse impersonal, aun los hijos a los padres diciendo mire mi padre, oiga mi madre. Cuando los padres los llaman les dicen oiga o mire, y ellos responden mande mi padre, diga mi madre, y si es otra persona dicen diga él (...). El castellano que hablan es bastardo y grosero. Regularmente son reputados por de buena crianza los que usan de las expresiones dichas. La pronunciación de las letras varía aquí mucho, las letras s y z pronuncian como d, v.g. por vecinos dicen vedinos, etc. (Martín Benito 2014:292).

Una vez puestos de acuerdo para tratar de investigar con detalle el habla de El Rebollar, había que empezar por la memoria de licenciatura (o tesina), que podía servir para desbrozar el campo de análisis. De modo que, aplicando la no escrita "teoría del compás" o de la onda, el investigador en ciernes inició la andadura por lo más cercano y conocido, tratando de explicar una serie de características diatópicas relacionadas con la cultura forzosamente oral de su familia y de sus vecinos de Robleda. El ensayo, aunque incluyó un inventario de los rasgos fonéticos y morfológicos rebollanos más llamativos en un apéndice (pp.184-191), se centró en el nivel léxico-semántico registrado en la cultura tradicional local y la ordenación de las 
fuentes utilizadas, como indican el título y el subtítulo (El léxico en la cultura popular de Robleda (Salamanca). Ordenación de materiales, 1972, 192 folios mecanografiados a un solo espacio). Era un "ladrillo" espeso, según el Director, aunque no un bello objeto por su presentación. Además de la tesis doctoral, gran parte de los trabajos personales tienen su germen en aquel rito iniciático, preparado en la emigración, cuando ya "el joven retraído", que también andaba algo retrasado (quizá simplemente por atrasado) en la vida, había decidido sacar los pies de las alforjas y, de una tacada, cumplió la mili, terminó la licenciatura, se casó y aceptó un contrato de profesor en la Universidad Católica del Oeste (Angers, Francia). Así se saldaban en parte casi impensables deudas contraídas tres o cuatro años antes. Atrás quedaba la primera y última posibilidad de una modesta beca, como colaborador en la elaboración del fichero lexicográfico para el diccionario de la Real Academia.

Antes de la salida para Angers (“¿Ya has mirado dónde está en el mapa?"), D. Alonso había recibido al "joven retraído" en su casa de la calle Pez Austral, cerca del Parque del Retiro. También estaba María Josefa Canellada, su esposa, a quien dirigió un saludo ("hola mamá") que, de pura casualidad, no dio lugar a una metedura de pata por parte del invitado (poco habituado a los tratamientos familiares urbanos). Este último llegaba acompañado de su novia, Françoise Giraud, a quien el Profesor regaló uno de sus ensayos sobre literatura clásica, acompañado de una caricia verbal ("toma, guapa"). Y el alumno, tímido pero atrevido, procuró disimular la confusión que le producía el agasajo (café y pastas) de aquellas personas a quienes admiraba y el asombro en el recorrido de aquella mansión, saturada de libros y de objetos de arte. Tanto es así que fue incapaz de guardar para él solo el descubrimiento de una verdadera pinacoteca privada dentro de un emporio de cultura, de modo que, en uno de aquellos comentarios irónicos del Profesor sobre sí mismo y sobre la importancia relativa de las circunstancias del entorno, dio la impresión de aludir a este episodio en un diálogo con otro alumno ("-Bah, yo mismo soy rico, y tengo un Velázquez. -Ya lo sé. -¿Quién te lo ha dicho? -Ángel”), porque D. Alonso podía hablar con la misma naturalidad de los cenojiles que de la mística de santa Teresa. La pareja recibió también un obsequio ("por si ponía casa"), un dibujo, titulado "Molino" firmado por Valdesaz ${ }^{2}$, que siempre ha sido su compañero de trasiegos domiciliarios en España y en Francia.

La estancia en el extranjero no facilitaba la consulta del Director de la tesis. Se hacía por correspondencia tradicional algunas veces (las cartas se han extraviado), con observaciones más bien lacónicas sobre muestras inacabadas ("el texto tiene muchas faltas"), también probablemente leídas por Ma Josefa Canellada, que por entonces estaba preparando una edición de las Farsas y églogas de Lucas Fernández (1976) y quería comentar alguna palabra del "llamado lenguaje y estilo sayagués". En general, había que aprovechar las vacaciones del verano para efectuar la encuesta de campo, muy laboriosa, asistemática e híbrida, combinando las preguntas indirectas y a veces, para completar, un cuestionario adaptado del abate Gabriel Guillaume para el Atlas Linguistique Armoricain Roman (1963-1966). Principalmente se trataba de escuchar a los presuntos hablantes dialectales, grabar sus relatos, tomar notas, cuyo resultado se transcribía y ordenaba durante el tiempo que

Pseudónimo de José María Gutiérrez González (Valencia de Don Juan, León, 1933 - Unquillo, Argentina, 2007), pintor, director de películas y de programas y series de televisión. 
dejaba libre el período lectivo (porque en el país vecino no ataban los perros con longanizas y también había que ganarse el garbanzo). Las teóricas vacaciones del verano u otras interrupciones de las clases también permitían las entrevistas con el Director, generalmente en la Facultad de Filología o en la Academia y a veces en su casa de El Escorial, donde correteaba algún nieto, o en todo caso una nieta, a quien designaba con el sobrenombre esporádico o habitual de Pitusa, a no ser que se tratara de Petisa.

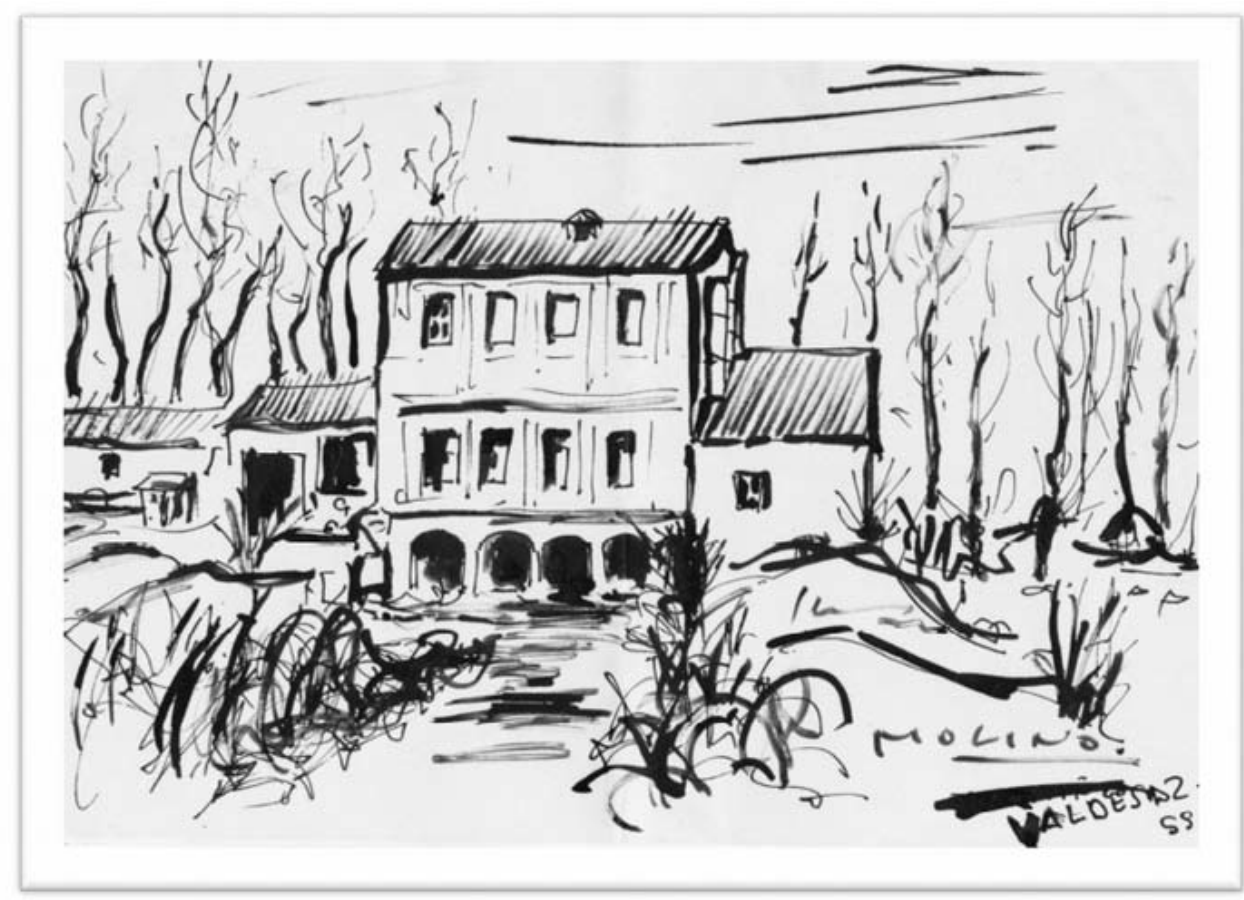

Figura 2: Molino, dibujo de Valdesaz.

Como el futuro doctor, más que la evolución histórica de las palabras, se sentía atraído por el dinamismo de la conversación y la relación de la variedad lingüística con las formas de cultura tradicional, el ciclo vital o del trabajo y la fiesta, todas ellas quizá ya en vías de desaparición, acelerada por la emigración masiva, la tesis llevaba un título consecuente, aunque resultaba algo paradójico. En todo caso, el estudio llegó a comuelgo y tenía el mérito de existir. Más que un "ladrillo" era un verdadero doble parpaing, dos bloques de cemento (Dialecto y coloquio en el habla de El Rebollar, 1976). Como la fecha de la lectura (07/04/1976) coincidía con la boda de un cuñado francés y Madrid quedaba lejos y a destiempo en sus vidas para los padres del doctorando, éste se presentó, algo provocador en su atuendo (chaqueta de ante, camisa rosa, sin corbata y con bigote vietnamita), sin otra compañía que la de un sobrino y tuvo por oyentes a los alumnos de Pedro Peira, con él mismo a la cabeza. El éxito de la prueba se celebró en La Posada, cerca de la casa natal de Cervantes en Alcalá de Henares, para comer migas fritas como plato principal, justo con los que cabían en una mesa: D. Alonso, Pedro, el aludido sobrino del recién doctorado y, por supuesto, este último. Con bastante retraso, como todo, llegó la publicación 
en dos partes, El habla de El Rebollar. Descripción, con prólogo de Alonso Zamora, 1982a, 315 páginas, y El habla de El Rebollar. Léxico, 1990, 325 páginas.

\section{El Maestro permanente}

Cuando esto sucedía ya el antiguo alumno había recorrido parte de su andadura universitaria en Francia, donde definitivamente había decidido asentarse, al cabo de una decena de años, esencialmente por razones familiares, para que los dos niños pudieran seguir una enseñanza secundaria sin trasiegos a destiempo. Para hacerse un hueco en el Hispanismo francés, además de la por entonces necesaria adquisición previa de la nacionalidad del país (ni soñada diez años antes), había decidido empezar por una tesis de tercer ciclo en lingüística general pero con materiales de onomástica (Onomastique $d u$ (sur)nom en espagnol, 1980, 425 folios mecanografiados), que no añadía nada como diploma a lo que ya tenía, y otra llamada de estado, o ès lettres en este caso (Onomantique: motivation et typification du nom propre (proverbial et populaire) en espagnol, 1987). Ambas fueron sostenidas en la universidad bajo la dirección de Bernard Pottier, un director que en su trato no se parecía en nada a Alonso Zamora (cuyo correlato, puestos a establecer odiosas comparaciones, en el plano relacional podría haber sido Maurice Molho, así como Bernard Pottier podía recordar la seriedad de Rafael Lapesa, los cuatro "queridos Maestros", a los que habría que añadir, para etapas anteriores, a Manuel Carrión, profesor del seminario conciliar de Palencia y subdirector después de la Biblioteca Nacional, fallecido en junio 2016). La maratoniana tesis de estado, a cuya elaboración se le calculaba una duración de diez años, hubo que rematarla a destajo a partir de 1984, cuando ya estaba empezada, para terminarla en la fecha tope de 1987, porque entraba en vigor otro plan (tesis única y habilitación para dirigir trabajos de investigación, basada en publicaciones y méritos en la docencia y la gestión administrativa universitaria). Hasta entonces la tesis de estado era requisito para postular a la cátedra de universidad (Professeur des Universités). Fue un hecho al año siguiente (1988).

En la consecución de esta meta profesional, D. Alonso había colaborado como Maestro permanente, no tanto en el plano pedagógico, lo que no estaba previsto ni ya era estrictamente necesario, sino mediante una sabia y discreta tutela, que se mantuvo en las décadas de los años ochenta y noventa. En sus última cartas (2005), todavía se interesaba por los reanudados estudios sobre la variedad lingüística rebollana, que se realizaban en las Jornadas organizadas en 2004 por la Asociación de Documentación y Estudio de El Rebollar (véase el anejo). Mucho antes el Maestro, con vistas a amueblar el currículum, había allanado el camino de las primeras publicaciones, también retrasadas algunas y otras abiertas a nuevos horizontes, como la toponimia y la paremiología, aglutinadas en torno a la semio-lingüística del nombre propio, aunque casi siempre circunscritas al ámbito de la cultura tradicional y popular, las relaciones entre la oralidad y la escritura, la literatura hispánica (Iglesias Ovejero 1981, 1982b, 1983, 1986a, 1986b).

A partir de los años ochenta al antiguo alumno retraído le entró la furia de la publicación de artículos, buenos, malos o regulares, en las principales revistas universitarias de Francia (París, Tolosa, Burdeos, etc.), algunas de España (Madrid, Barcelona, Salamanca, etc.) e incluso de colaboraciones en otros países (grupo PaTRom en Tréveris, Roma, Lisboa, etc.), que a veces requerían encuentros previos. 
Intrépido, pero no temerario, a estas reuniones asistía cuando era posible hacerlo sin abandonar el plancher des vaches. En caso contrario, solamente viajaba la comunicación escrita, porque los viajes por mar o por aire están reñidos con su predilección por la tierra seca.

Don Alonso estaba al corriente de estas "aventuras universitarias en la República Francesa" (ironizaba), al tiempo que colaboraba, de cara al trabajo más ambicioso, que era la mencionada tesis ès lettres (1987). Antes de su jubilación recibía en el despacho del seminario de Filología Románica, cuya biblioteca estaba casi siempre accesible gracias a la buena disposición de la bibliotecaria Concepción Martínez. Como secretario de la Real Academia, facilitó la consulta del fichero lexicográfico para el análisis de los nombres propios, que él estimaba casi resuelto de antemano, dado que la sabia Institución no se había ocupado del estatuto lingüística de tal signo ("enseguida vas a acabar, porque la Academia casi no los ha incluido"). Pero había más materia de la prevista, porque había nombres comunes deonomásticos, que, como el estudio clásico de Migliorini (1927), habían cambiado de subcategoría nominal debido a usos metonímicos de nombres propios de lengua, pero éstos también podían ser resultados de un empleo análogo, por antonomasia, de sustantivos y adjetivos, como es fácil de comprobar, por ejemplo, en la evolución histórica de los apellidos.

De igual modo, a diferencia del francés, no se consideraban nombres propios en español las designaciones establecidas de grupos étnicos (etnónimos o gentilicios), así como los motes de colectividades humanas de personas, analizados como parte de los blasones populares, o dictados tópicos en la terminología tradicional. No solo interesaban a Camilo José Cela, que los denominaba pseudogentilicios, Alonso Zamora (1943) los había descrito en El habla de Mérida y sus cercanías. Por ello se eligió este tema para las publicaciones en su homenaje al final de los años ochenta (Iglesias Ovejero 1989).

\section{Colofón}

En suma, el seguimiento de Alonso Zamora duró mientras le alcanzó la vida, como sucedería con otros antiguos alumnos. Solamente se perdió el estudio de la represión franquista y los ensayos previos, que se iniciaron cuando el Maestro ya estaba en el último tramo de su larga y provechosa carrera por este mundo y, recordando con el Eclesiastés que la vida del hombre "es apenas el rastro de una nube", esperaba una que le sirviera de vehículo en el viaje sin vuelta (que "al desflecarse [llevara] un gancho, una escala, algo a lo que agarrarme y cumplir mi aventura" (La Granjilla, 22/01/2005). Obviamente, La represión franquista en el sudoeste de Salamanca (1936-1948) abordaba un tema muy alejado de la Filología (Iglesias Ovejero 2016). Él debía de sospechar la terrible brecha, de la que nunca se hablaba (no se podía hablar) explícitamente, producida en la familia por aquella sangrienta persecución de 1936. Quizá el "retraimiento" que había detectado en el alumno tuviera que ver con aquellos sucesos vividos por ósmosis familiar. Podía haber percibido algunos claros atisbos en los comentarios de un álbum de fotografías, tomadas a modo de ayuda memoria de "las palabras y la cosas", y por ello presentado como complemento de los materiales utilizados en la tesis por él dirigida. La iniciativa no debía de entrar en los usos y costumbres de aquellos ritos académicos, $\mathrm{y}$, como presiden- 
te del tribunal, lo censuró y excusó al mismo tiempo (" ¡No nos vamos a leer todo esto ahora!"). Sin embargo, D. Rafael Lapesa, que no era un novato en esas lides y conocía el protocolo, se puso a ojearlo sin parar ni hacer casi ningún comentario hasta después de la prueba. Por cierto, el doctorando también había sido "alumno guadiana" de este otro Maestro, una de las últimas personas que vio antes de salir para Francia y de quien recibió en anticipado aguinaldo un ejemplar de su Historia de la lengua española (1942) con autógrafo incluido.

A excepción de este secreto que bien merecía haber dejado de serlo, Alonso Zamora fue confidente epistolar del antiguo alumno desde que éste marchó al extranjero. Desgraciadamente, no solamente las cartas más o menos anodinas sobre dudas académicas, sino otras más serias, escritas en respuesta a saludos del ciclo navideño o anuncios de acontecimientos domésticos (le gustaba estar al corriente de los avatares de la pequeña familia y solicitaba fotos de los niños), se han extraviado en alguna de las mudanzas domiciliarias. Solo ha aparecido una decena, tres ellas de 2005 , sin duda cuando presentía la llegada de aquella nube viajera. También permanecen en el recuerdo los intercambios epistolares sobre los momentos más tristes del ex alumno: el nacimiento del primer hijo muerto (1972), el fallecimiento de un amigo común (1995), el trágico accidente de un yerno (1998), la muerte de un hermano (2000). Parece ser que hablar de estas cosas es de mal gusto entre personas educadas, pero no es mejor la opción de quedarse sin saberlas a tiempo, como sucedió con el fallecimiento de $\mathrm{M}^{\mathrm{a}}$ Josefa Canellada (1995) por falta de mensajero (su marido, salvo error, le había dedicado "el mejor silencio"). Don Alonso era de una exquisita discreción sobre su entorno familiar a cuyos miembros nunca mencionaba de una manera directa ("creo que he visto por ahí el coche que yo pago"). A diferencia de su alumno, que también le enviaba buenas noticias (los nacimientos de los niños Cécile y Miguel o el bautizo de Hélène, una estancia casi feliz en Elche, etc.). De su fallecimiento todo el mundo pudo enterarse por los periódicos.

En la correspondencia adjunta pueden apreciarse algunas de las vivencias y opiniones expuestas. Su contenido era lacónico al principio y más elaborado después, sobre todo en la última época, cuando ya las visitas de antaño hubieran resultado inoportunas y fatigosas. En esencia se confirma que el gran filólogo y humanista que era D. Alonso Zamora Vicente supo combinar la tutela profesoral y una relación afectiva y respetuosa con aquella pareja hispano-francesa conocida en el segundo lustro de los años sesenta.

\section{Referencias bibliográficas}

Canellada, Ma Josefa (ed.) (1976): Farsas y églogas de Lucas Fernández. Madrid: Castalia.

Cortés y Vázquez, Luis (1979): Cuentos populares salmantinos. Salamanca: Librería Cervantes, 2 vols.

Criado de Val, Manuel (1980): Estructura general del coloquio. Madrid: Consejo Superior de Investigaciones Científicas.

García de Diego, Vicente (1946): Manual de dialectología española. Madrid: Instituto de Cultura Hispánica.

Guillaume, Gabriel (1963-1966): Atlas Linguistique Armoricain Roman. [Angers]: CNRS. 
Iglesias Ovejero, Ángel (1972): El léxico en la cultura popular de Robleda (Salamanca). Ordenación de materiales. Madrid: Universidad Complutense de Madrid [Tesis de licenciatura, inédita].

Iglesias Ovejero, Ángel (1976): Dialecto y coloquio en el habla de El Rebollar. Madrid: Universidad Complutense, 2 vols. [Tesis doctoral, inédita].

Iglesias Ovejero, Ángel (1980): Onomastique du (sur)nom en espagnol. París IV. Universidad de la Sorbona [Tesis de 3er. Ciclo, inédita]

Iglesias Ovejero, Ángel (1981): "Eponimia: motivación y personificación en el español marginal y hablado". Boletín de la Real Academia Española 61:297-348.

Iglesias Ovejero, Ángel (1982a): El habla de El Rebollar. Descripción, prólogo de Alonso Zamora Vicente. Salamanca: Universidad, Diputación Provincial.

Iglesias Ovejero, Ángel (1982b): "Estructuras mítico-narrativas de Réquiem por un campesino español". Anales de la Literatura Española Contemporánea vol. 7, 2:215-236.

Iglesias Ovejero, Ángel (1983): "Nominación marginante en el picarismo literario y el folklore". Revista de Filología Románica 1:137-181.

Iglesias Ovejero, Ángel (1986a): "Romance de la Bastarda". Revista de Dialectología y Tradiciones Populares 41:236-239.

Iglesias Ovejero, Ángel (1986b): "El estatuto del nombre proverbial en el refranero antiguo". Revista de Filología Románica 4:11-50.

Iglesias Ovejero, Ángel (1987): Onomastique: motivation et typification du nom propre (proverbial et populaire) en espagnol. París IV. Universidad de la Sorbona, 3 vols. [Thèse de Doctorat d'Etat, inédita]. Reproduction micrographiée: Lille-Thèses, ISSN 0294-1767, 87. 17. 05332/88.

Iglesias Ovejero, Ángel (1989): "El blasón popular de los Farinatos y sus aledaños: Ciudad Rodrigo, El Rebollar y Campo de Azaba y Argañán", in P. Peira et alii (coords), Homenaje a Alonso Zamora Vicente, vol. II, pp. 171-187. Madrid: Castalia.

Iglesias Ovejero, Ángel (1990): El habla de El Rebollar. Léxico. Salamanca: Centro de Cultura Tradicional.

Iglesias Ovejero, Ángel (2010): "Situación del habla de El Rebollar (Salamanca): analogías y contrastes con las hablas extremeñas. Lletres Asturianes 103:35-59.

Iglesias Ovejero, Ángel (2016): La represión franquista en el sudoeste de Salamanca (1936-1948). Ciudad Rodrigo: Centro de Estudios Mirobrigenses.

Lapesa, Rafael (1942): Historia de la lengua española. Madrid: Gredos.

Martín Benito, José Ignacio (2014): "El Rebollar en el siglo XVIII, visto por un presbítero sevillano. El viaje de Gálvez en 1755". Cahiers du PROHEMIO 12:287-299.

Menéndez Pidal, Ramón (1906): El dialecto leonés. Madrid: Revista de Archivos, Bibliotecas y Museos.

Migliorini, Bruno (1927): Dal nome proprio al nome comune. Studi semantici sul mutamento dei nomi propri di persona in nomi comuni negl'idiomi romanzi. Florencia: Olschki.

Zamora Vicente, Alonso (1943): El habla de Mérida y sus cercanías. Madrid: Anejo XXIX de la Revista de Filología Española.

Zamora Vicente, Alonso (1960): Dialectología española. Madrid: Gredos. 
186

Iglesias Ovejero, Á. Rev. filol. rom. 34 (Núm. especial) 2017: 171-196

8. Apéndice: Ilustraciones y correspondencia

$$
\text { 29. } 17-75
$$

Queris Angel:

revo, anfio en coe tors aie hien alook, in lowers. Ya me lo dins. En cuars a $l$ tim faunbir salds-. Yc cllh. reuns ste veraus. -

th voon dive,

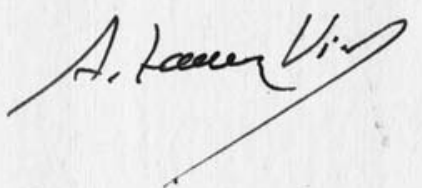

$5 . v-73$

Eshore hene!!! 


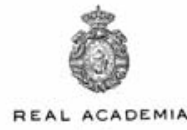

ESPAÑOLA

Angel iglesias:

amo Dios manda,y que medre de la mejor manera.Y que no moleste a la herma a mayor. Es una noticia estupenda.

De la teais, como mejor te parezca.Desde luego que me pa_ rece será mucho mejor verlo todo o lo más posible junto,para poder estar sobre l conjunto. Estoy tan disperso en mil cosas, que a veces no se si es que ya no entyeno nada. Bxamenes, jaleos de todo tipo, la Academia,tesis... El plan que me mandas, eatupeado. saimo y a acabarla. Siempre podremos char. lar tranquilamente un rato on el verano, 10 suriciente.

De la presentación material de la tesis: mecanografiada, cinco ejemplares, creo. Bgo es facil.Pedro va a leer la suya ahora,y te 10 explicara coa detalle. En cuanto al dato de la lectura, no tengar reparos. Suele salir siempre bastante mejor/de lo que el doctorando piensa.

Te ecribo a vuelta de correo,en un respirillo.una tarde de examenes que acabo pronto y/me bive a casa derecho,coa la esperana de

poner mi correo al dia, y he empezado por ti. Un gran abrazo,
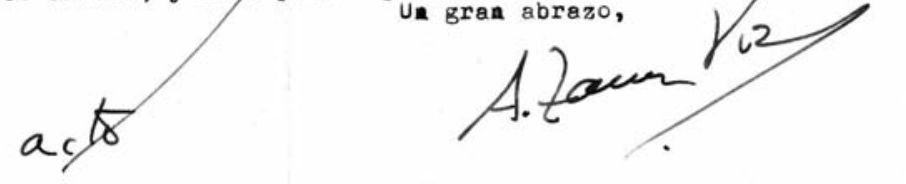
pañada de la noticia de tu nueva chica. Nuestra enhorabuena más a_ fectuosa. Deseamos que la familia vaya prosperando y creciendo,sin l'imites.

Mi salua va regular. No sé si sabes que este otoño he vuelto a pasar otra pulmonia.Yakan dendo muchos los avisos. Bueno, Dios ayudará.

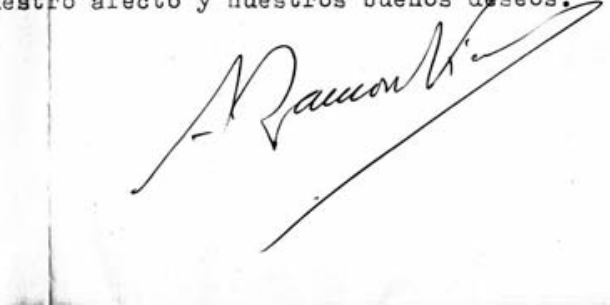


188

Iglesias Ovejero, Á. Rev. filol. rom. 34 (Núm. especial) 2017: 171-196

Lafrainith, II, jucedi, 1995.

realacademia feovido tupel I fanión:

une elequi ta calk. Podro ceessio de en coin or de vuluern. Pare cia oe reaccionela lim al taveciadr, pe-...

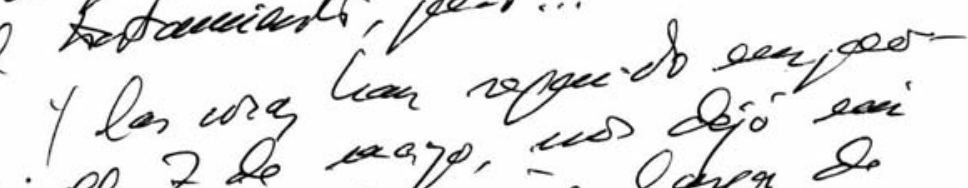
rand: el 7 be rayp, us bojor evi

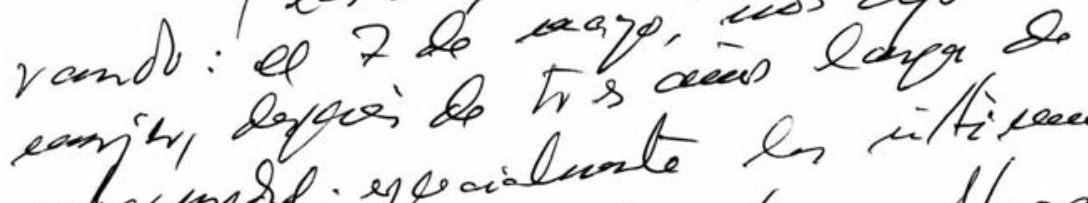
enfermahd, perailuate en rittivenes ocho noses han nido atvors, Aleor

interto porver orden en ste caros cer ba

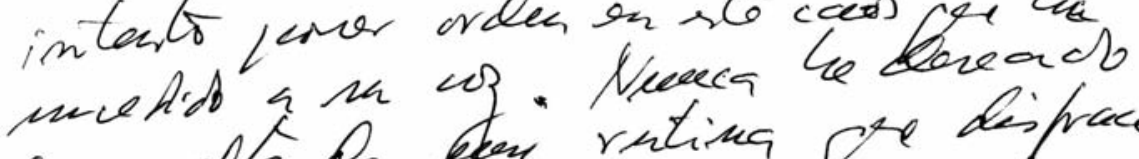
a vevela de beng ruting pre disfrace la realide ingrats.

Pess se ces Dis yoree siemper. $y$ on in suaceo deredea uticio.Carieñ vars torb cow his.

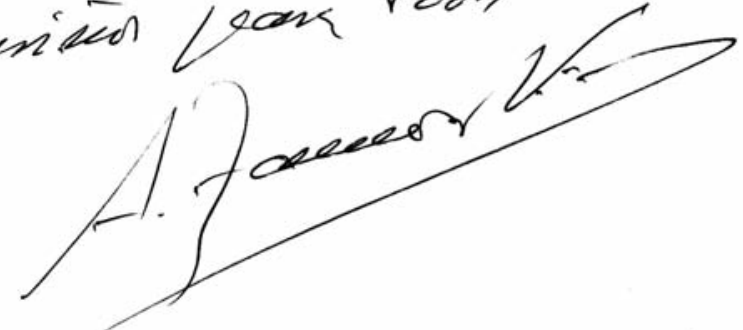




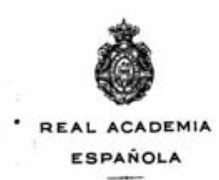

-

La Granjilla,11,marzo,1997.

\section{Queridos 1 glesias}

¡Qué foto preciosa,la del grupito familiar,tan orondos como se os ve...! Mi enhorabuena.Revela satisfacción, orgullo por el pasado común, exhibieión gozosa de los chavales. iY qué buena ointa tenéis todos! iA vivir,que son dos días!.

Ye alegran todas las noticias.yo poco puedo contar. Ða te supondrás todo lo quepor aqui va pasando,y cómo es de complejał la vida. Bstoy cada día más encerrado en casa, pues veo pasar al lado un tumulto de sandeces organizadas, hipócritamente rlevestıdas déprogresismo,y paladeo la certeza que la única manera de mantener la dignidad en esta tierra es ser un solitario. Bscribo alguna cosilla (acabo de entregar una gordinflona Historia delka Academiq), repaso mis cuer tecillos, y veo crecer a loshietos.Y ya está. Alguna vez viene alguien a sacarme de esta paz,y pico,hago una excursioncita, corta, que las piernas no dejan cometer excesos,y voy ti/fando.

Mehablas de losfproyectos del verano.Yo no hago ya planes. Ne entrego a los que $\mathbb{Z}_{\text {a }}$ familia dictamine.suelo acercarme a Santander, a buscarlos,en ayosto,y me vuelvo con ellos.otras veces, me pego,otras me acerco alf guna cĐudad cercana unos días.lo mejor es quedarse en cas, no hace calor, cuido el jardín,me siento útil.Las plantas agradecen el mimo y no salen por peteneras, como los humanos. Bn $f$ in, el que no se colnsuela es porque no quiere.

veo que habéis tenido también despracias t’amiliares.Aqui no faltan. Los años se notan, y voy siendo un superviviente.Cada semana, cae alguien y lo per es que lo ves venir,y que no se evitr,y que,en muchos casos,esas enter medades atroces nos hacen desear la rapidez... En fin, qué el mundo está mediana-

mente hecho.Nosotros, hace unos quince diss, henos tenido que ir a Asturias:mut mente hecho. Nosotros, hace unos quince dís, el último hermano que quedaba de Marí Josera:yivía solo, en la aldea, hecho un ermitafio, pero feliz. Ahora vienen los lins juridicos,que se las traen. Supongo qle quedariais nartos del calor y los empyjones en el Misthi.yo lo ví así, en dos sesiones, de estudiante.tero rhorr hefido alguna vez,y procuraré volver, por los Santos, que lo hacen de una sentadaly solo para los realmente interesados, lejos de ferias, cohetes y gente de vacaciones. 1 sobre todo hace fresquito,y hay sitio en los noteles de Alicante. (Las entradas se consiguen por medio de algu na persona local, de la "niversidad).Qubero volse consiguen por medio de algu na persona lo del barulio estruendoso. Hay uma grabaver otra vez.Ks hermosísimo despojado del barullo estruendoso. muy buena, dirigida por Uscar Esplá,el gran musicologo, que estudio muy bien el Misterio.

claro que me gustará veros. Helefonead si pasais, para aue bap nos prngamos de acuerdo. Bsta casa mía esuá donde Cristo dio laß̧ tres voces, pero se llega.

un gran abrazo para todos. Vuestro,

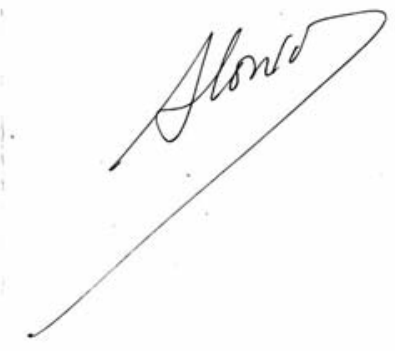




\title{
Fundación Antonio de Nebrija
}

\author{
La Granjilla, I (, enero,1999
}

Mi querido Angel Iglesias y familia:

qué pena la noticia de la desaps ción del chaval... "Cuando más ardía el fuego,echaste agua," "quje dice el poemademanrique. No te voy a decir nada.sé que las palabras nos ven.Bs más claro un gesto de manos tendidas,y pensar juntos en la II no de Dios,que todo 10 lleva y todo lo da.Bl consuelo y la desesper ción.Dale un gran abrazo a Cecile, y estoy seguro de que, a vuestro ] do, volverá atener paz de espiritu, sofifos interior y esperanza en el porvenir.Y a vosotios os toca el papel silencioso de ir empujando un carro que ya conocéis, fpero que ahora hay quetratar de otro modc Ahora ya sabe 10 que son las estúpidas jugarretas del destino...

Os deseo ánimo $\mathrm{y}$ fe en vosotros mismds.

Si,he pasado unas fiestas tranquilas, hetidito en casa,y

asomando de cuando en cuando la nariz al jardín.Ha hecho mucho fríc $y$, a pesar de la protección, mis bronquios han terminado por protest y he pasado dlas malos, muy malos.Yà cada vez que se hacen presentes es con peor cara.La vejez no perdona,y los alifafes crecen. Este ver no último, me descubrieron una de esas sombras de corazón,y llegó ur. alarma más...No para mí,que ya me considero un trasto inútil.Han id desapareciendo 108 amigos, los colegas con los que tenía trato... Soy un superviviente, y es eptraña sensación esa falta de una compańís. Por otra parte, el país está extraño, raro, no caso con nada.Todavía soy vefestorio grunón, pero....A ver si se-acaba este periodo de tos, (¿quince dias aún?,y salgo con libertad,y te mando un libr/ejo que me están terminando.Quizá así podamos mantener un engañoso diálogo por encima de los quilometros.

He mirado con mucho interés el libro de los romances. $Y$ he leído,en la cama,muchos,y toda la introducción. Veo la enorme dista Cia a que nos encontramos los de mi tiempo de los métodos y trato de ah ra.Pero todo vale:todo se escribe paratodos,tam presentiphuam futu ris... Ya no me acuerdo ni de cuándo estuve en El Rebollary sin embargo,se me pone en pie en Iffmemoria la luz de la mañana aquella, ca Cortés (itambién muerto!) intentando leer letras de la flor nueva de

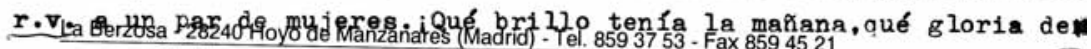
C/ Pirineos, 55 - 28040 Madrid - Tel. 3116602 - Fax 3116613 
rramada por campos,casas,horizontes... Y ya no puedo poner más en mi memoria en claro.Sé que dormimos en una pensión humildíaima de Ciudac Rodrigo... Otra vepfuimos a Gata, Puerto de Perales abajo. Fuer on mucl los viajes por tođo aquello.También Maluquer desaparecib,y su mujer y no sé nada de 108 hijos:se hicieron algunos catedráticos de Institı to, muy pronto, los mayores;los pequeños los he visto en torno al nune bien ponderado Consejo Buperior de Inw.Cientificas....

No creo que la intervención de Lorca sobre Monleón tenga । máxima trascendencia.Sí, la divulgación, copiosa, exagerada, ha venido da pués (¿Sabes que le han llamado,criticos repistonudos, compositor, poi ese puffado de cancioncillas?) No:y tú podrías poner mucho orden en e: barullo. La preocupación popho popular tradicional nació con/la publica ción del Cancionero de Palacio, de Brbieri,que fue la gran fue nte de formación deflos del $27, y$ se redonded(ino lo dicen, tunantes!) con la colección de Cejador. Fntre tanto habían ido saliendo camcigoneros lo cales y regionales, de muy vario valor.No sé por qué pienso ahora que su aparición en el mundo "serio"/es el romancero de Juan Menéndez Pic asturiano.Para mí, desde luego,era del colegio:yo pertenezco a unas ga raciones educadas en la Institución(mejoreen sus ideas) y visitábamo puebloga granel y cantábamos hasta enfermar de la garganta. Lo que vo. \$otros habéis hecho está muy bien.También otro viejo alumno mío hace -cosas parecidas en la vertiente sur de lasierra,por el Vallé del Je: te.Y zsalen cosas muy curiosas.

Bnhorabuena por ese libro.Seguramente Cecile, que se reencontará, podrá seguir trabajando, y hasta poner orden en la' ciencia novía ma. ¿Sabes que ya se'habla de asturiano exterior, en ese łincón de Sa: msnca? Claro quefambién se habla de gallego en el Trevejo. Bstamns bu nos. Te dejo. Vuelvo a enviaros mi mejor abrazo, con mi renovado cariño. Vuestro,

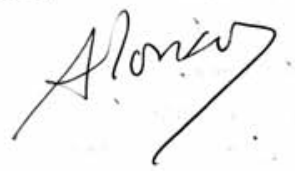


Mi querido. Angel lglesias:qué placer leer tu carta,tan llena de ese español fluyente y enjundioso,que aqul la gente no conoce nada... No te pasmes:nadie sabría aquí, a no ser un monumenta nacional en ruinas, como yi, qué quierés déir con de luto a la manera antigua, qué es el relente, qué el regustillo amargo.el verse de higoa a brevas.. Frases que yo sigo escribiendo y que me censuran por difíciles o desconocidas. No creo que haya algun memo ofial queptiense que mollas invento yo ... En fin, un español mag nífico.(No digamos duperle más sahgre al Cristo, o estar de reata en la mag
puerta...)

Entiendo muy bien todo lo que dices de tus chicos. Aqupi nos pasa - lo mismo, ya con lyos nietos. Cada vez me escalofría más pensar en su porvenir,con la atrozmente mala eneseńanza de la Universidad oficial,y los desma nes sociales como norma aceptada o, por 10 menos, disculpada. IA tristeza me invade por todas partes. Añde a eso mi salud que ya ha entrado en el declive de los años (voy a cumplir dentro de unos días 85) y aue empieza a no so portar medicinas, ni las más elementales de siempre, a las que me he declarado alérgico, y la soledad creciente, aunque todos luchen por evitar aue se nete, y tendrás una idea de cómo voy tirando. Sin embargo, contento. Aún puedo leer 10 que quiera, ir a donde quiera, y tenerftratos con quien quiera. Bsto úl. timo es impagable regalo de todas las mitologías y sociedades paradisíacas.
En fin...

Nefusta tucho la idea de que os acreféis la casa del pueblo. Ahora, en algún paseo por los alrededores madrilenos, he descubierto que hay casonas maravillosas, de fines deI XVIII, muy bien arregladas, que, hace pocos axos, cuas do encontramos esta donde vivo, nos habrían costado poco y habríamos podido

arrechar muy bien; a nuestro capricho. La falta de comunicaciones buenas para ir o volver de Madrid,nos paró. Ahora son un ensueño. Pero no vale lapena sofiar en ret6ospectivo:hay que apechugar. De todos modos, los vecinos rían iguales, y entonces, qué le yamos a hacer, ia joderse tovan... ! Ojalá os salga bien el proyecto. De eso del uranio,ya ves lo que se está destapando con la guerra de los Balcanes. No sé qué es peor:si la enfermedad en sí,con la desbracia collectiva que acarrea,o la necedad de los diputados hablando doctoralmente de el problema.Todós tienen una carga de uranio y cagonio, lo más explosivo que se conoce,dentro de sus respetables melones.(Si son melones, que, en algunos, es cosa muy dudosa...) Siento lo de tu hermano.Yo verás cómo los sabiazos no demuestran jamás la relación:quizá dentro de veinte, ve inticinco afios, cuando ya no haya cosa me jor quepecordar, digan aquello de "conviene cerrar los establecimlentos de bebidas una horita antes:se reducirá c nsiderablemente la interacción efusivo-magnetofónico-cancerosa del uranio, no ya empobrecido, sino harapiento y sarnoso" iToma castafia...!

Te agrasezco mucho tu récuerdo. Pásale mi afecto a todos los tu yos,y para vosotros Kodo mi viejo afecto. Que el año y todos los años os traigan serehidad al alma y bienestar al cuerpo.

Conel mejor abrazo,

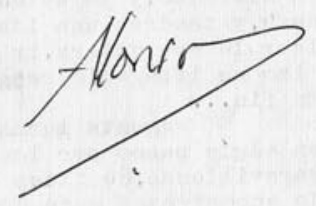


Iglesias Ovejero, Á. Rev. filol. rom. 34 (Núm. especial) 2017: 171-196

193

La farjills, 22, 1,2005

REAL ACADEMIA ESPAÑOLA

presids Angef Ifleng et uxor ma: Me alegró vacteo racesta cank, salar de vorton an detulle. Me alegra vem entregats al heda de vivir, iereds a is verestor vecer y kear, a reos. to lado, un nue no ounado. Yo nipo imatil, vejétionio in rescepdio. Ya na pova The ciêos gere ecei kid i la vertana del jardin, viendo peaser lar wuhes. Creo pa s el ticleviater al per Die (y re greach tam ancho) gere la ridh de lcoulve is "queng el ratio de erea mula". Yo

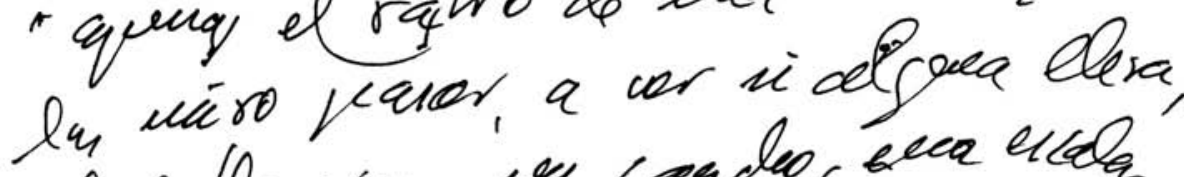
al deplecurne, un candeo, beca ruely 
194

Iglesias Ovejero, Á. Rev. filol. rom. 34 (Núm. especial) 2017: 171-196

atp a lo su agarravine y cumelir

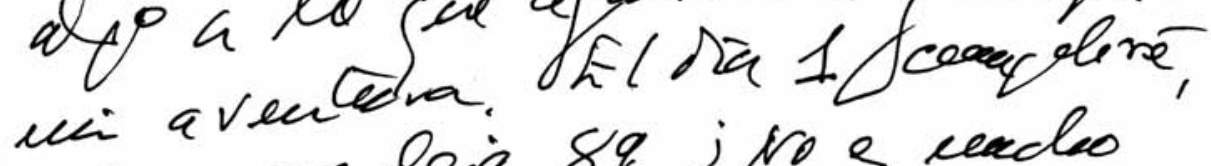
ie sis ua deja, 89. ¿ No s ceacleo feer Gecera?

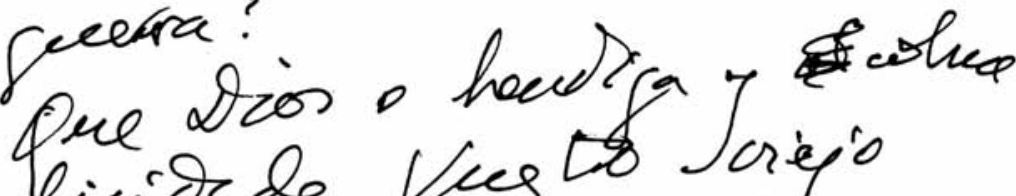
de plicidrds. Vues sorio acing.

A.Zenewr Viceel

Mandaue eas cectas de los riterdin notre El Relollar. 
Iglesias Ovejero, Á. Rev. filol. rom. 34 (Núm. especial) 2017: 171-196

195

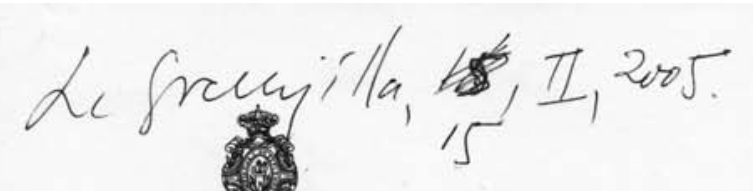

REAL ACADEMIA ESPAÑOLA

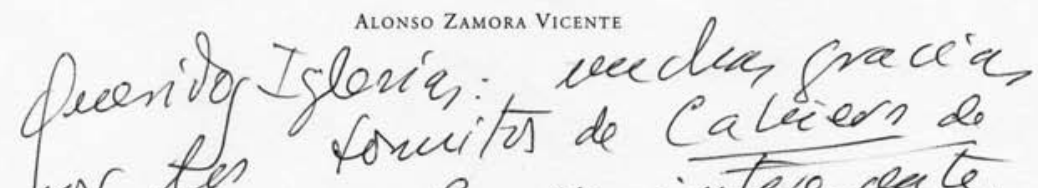
nor tes sonciitos de Calciedn de PREM Mis. fon uy intere ceats,

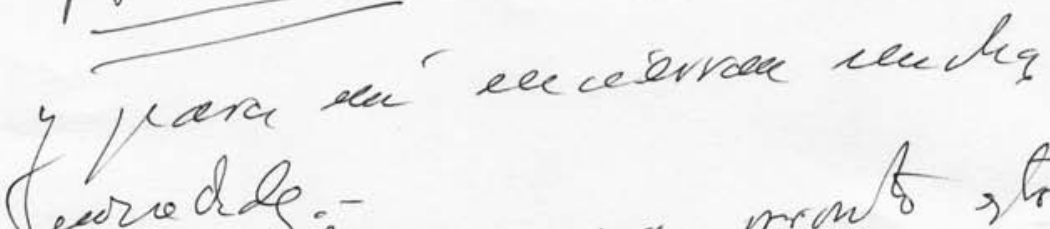
verredg.-

Orili re vayan pronto its prion/(loogrtí nevaado), y way pollawas feariticers, y a medro refuelth, me de verelvan un yoro de coriego: ene hace reudra folata.

Coniten vara torb. Vee tro,

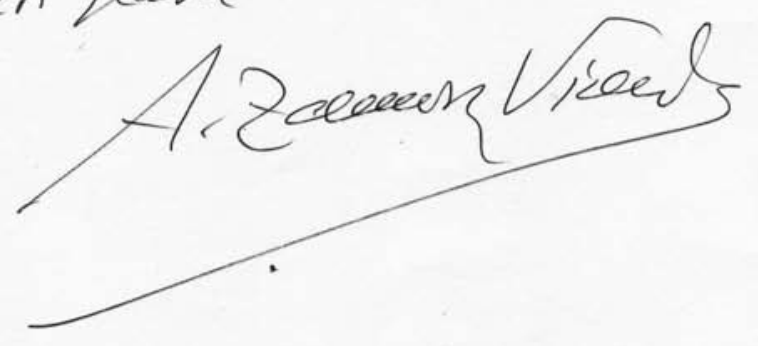


196

Iglesias Ovejero, Á. Rev. filol. rom. 34 (Núm. especial) 2017: 171-196

La Gacailla, 5, agent, 2005.

REAL ACADEMIA ESPAÑOLA

Mi reandofo Irancoine y Aupl I plicy: reaik veator cati, onel praquere de

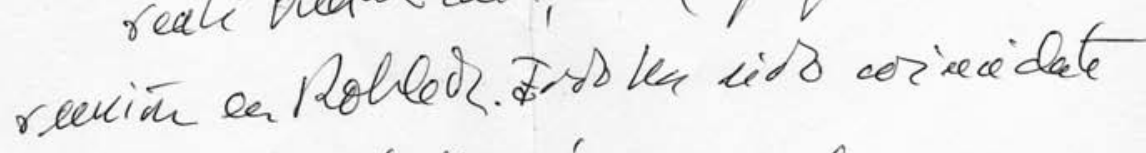

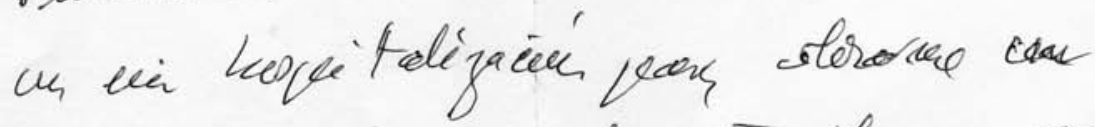

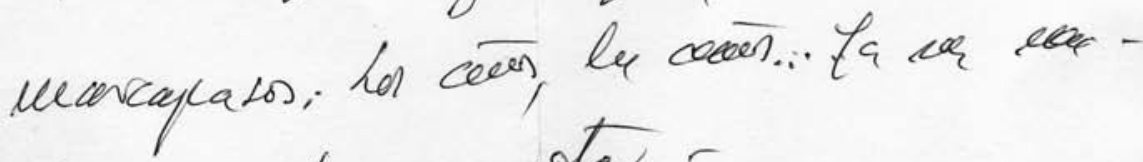
cles, y re hack wotor.

di er corra here ver tort lo goe vivig de exitay de gray. Perdual exi deratura lettr-

Alrapora eacdeo corino vector,

A. Zaman Viced 